This preprint is part of the supplementary materials supporting a manuscript that has been accepted for publication in Science of the Total Environment. This document is submitted to EarthArXiv as is and is not intended to be updated. Once printed, the final version of the manuscript will be accessible via the 'Peer-reviewed Publication DOI' link on the right-hand side of this webpage. Please feel free to contact any of the authors; we welcome feedback. 
Refer to as: Diaz-Maurin, F.; Yu, J.; Ewing, R.C. Socio-technical multi-criteria evaluation of long-term spent nuclear fuel management strategies: A framework and method. Science of the Total Environment In press. Available at: 10.31223/X5459S.

\title{
Socio-technical multi-criteria evaluation of long-term spent nuclear fuel management strategies: Supplementary method
}

François Diaz-Maurin ${ }^{1,2}$, Jerold $\mathrm{Yu}^{2,3}$, Rodney C. Ewing ${ }^{2,4}$

${ }^{1}$ Decidia Research \& Consulting, 08202 Sabadell, Barcelona, Spain

${ }^{2}$ Center for International Security and Cooperation (CISAC), Stanford University, Stanford, CA 94305, USA

${ }^{3}$ Department of Statistics, Stanford University, Stanford, CA 94305, USA

${ }^{4}$ Department of Geological Sciences, Stanford University, Stanford, CA 94305, USA

\begin{abstract}
The paper presents supplementary information about the framework and method for the socio-technical multi-criteria evaluation (STMCE) of spent fuel management strategies (Sci Total Environ, In press; Available on EarthArXiv at DOI:10.31223/X5459S). The STMCE approach consists of (i) a multi-criteria evaluation that provides an ordinal ranking of alternatives based on a list of criterion measurements; and (ii) a social impact analysis that provides an outranking of options based on the assessment of their impact on concerned social actors. STMCE can handle quantitative, qualitative or both types of information. It can also integrate stochastic uncertainty on criteria measurements and fuzzy uncertainty on assessments of social impacts. This paper presents (1) a detailed discussion about the social multi criteria evaluation framework on which STMCE is based; (2) a review of existing
\end{abstract}


Refer to as: Diaz-Maurin, F.; Yu, J.; Ewing, R.C. Socio-technical multi-criteria evaluation of long-term spent nuclear fuel management strategies: A framework and method. Science of the Total Environment In press. Available at: 10.31223/X5459S.

multi-criteria techniques and previous applications to nuclear waste management; and (3) a detailed description of the mathematical procedures used in the STMCE method.

Keywords: radioactive waste; geological disposal; interim storage; multi-criteria analysis; conflict analysis; impact assessment

\section{Appendix B. Supplementary method}

\section{B.1. Framework}

Multi-criteria decision analysis (MCDA) emerged as a sub-discipline of operational research also known as "the science of decision making" (Gass, 1983; Hillier and Lieberman, 2015). MCDA provides a framework for stakeholders to structure their thoughts about the pros and cons of different decision options. Formally, a MCDA method can take the following definition: "A multi-criteria method is an aggregate of all dimensions, objectives (or goals), criteria (or attributes) and criterion scores used. This implies that what formally defines a multi-criteria method is the set of properties underlying its aggregation convention" (Munda, 2008, p. 6). Because the types and properties defining the aggregation convention can vary broadly, many MCDA approaches and methods are available to decision makers that can be applied to a virtually infinite number of specific decision problems often requiring the method to be adapted to each situation (Doumpos et al., 2019; Greco et al., 2016). Despite their differences, MCDA methods all aim to address the trade-offs between decision options by means of a mathematical convention that explicitly evaluates multiple conflicting criteria. However, as pointed by Munda (2008, p. 7): "In general, in a multi-criterion problem, there is no 
Refer to as: Diaz-Maurin, F.; Yu, J.; Ewing, R.C. Socio-technical multi-criteria evaluation of long-term spent nuclear fuel management strategies: A framework and method. Science of the Total Environment In press. Available at: 10.31223/X5459S.

solution optimizing all the criteria at the same time (the so-called ideal or utopia solution) and therefore compromise solutions have to be found." This is particularly true of decision problems that convey potential health and environmental risks such as the remediation and management of hazardous substances.

To address this issue, the social multi-criteria evaluation approach has been developed for policy evaluation and conflict management in environmental and public policy decisions (Munda, 2019). This approach has already demonstrated its applicability in different typologies of decision problems and in various geographical and cultural contexts (Greco and Munda, 2017). These include economic development of regions and cities, rural electrification, food production, water resources management, aquatic systems protection, coastal zone management, environmental management in arid regions. For a recent review of real-world applications of the social multi-criteria evaluation approach, see Munda (2019).

One of the main advantages of social multi-criteria evaluation-in contrast to MCDA - is its ability to deal with various conflicting evaluations by achieving the comparability of incommensurable dimensions and values. In particular, the social multicriteria evaluation approach extends the multiple criteria decision support to also include the concept of social actor, thus allowing for an integrated analysis of the problem at hand (Munda, 2008, 2004). However, unlike other participatory or stakeholder engagement approaches, Munda's approach considers public participation as a necessary but not a sufficient condition for successful evaluation (Munda, 2004). In addition to participation, transparency also increases the chances of successful public policy decisions (Stiglitz, 
Refer to as: Diaz-Maurin, F.; Yu, J.; Ewing, R.C. Socio-technical multi-criteria evaluation of long-term spent nuclear fuel management strategies: A framework and method. Science of the Total Environment In press. Available at: 10.31223/X5459S.

2002). A social multi-criteria evaluation process will be transparent if, in representing a given decision problem, the assumptions used, the interests and values considered are declared (Munda, 2004). Munda's social multi-criteria evaluation also seeks to overcome the pitfalls of technocratic approaches to decision support by allowing the integration of different methods of sociological research. That is, social multi-criteria evaluation primarily aims at searching for compromise solutions by highlighting distributional conflicts among options and social actors. By searching for compromise solutions rather than optimal solutions, social multi-criteria evaluation acknowledges that scientific knowledge and technological systems are themselves social constructions (Bijker et al., 2012; Jasanoff, 2006).

In operational terms, the social multi-criteria evaluation process consists of seven main steps that are presented in Fig. B.1. The process starts with a description of the relevant social actors (step 1), which can include an institutional analysis. Then, the process defines the social actors' values, desires and preferences (step 2) performed either through focus groups, interviews or questionnaires. This is an essential, yet very difficult, step of the social multi-criteria evaluation process because of the ambiguity of capturing what people really think as well as the difficulty of considering a statistically representative set of members for each relevant social actor. The process accounts for such ambiguity by introducing the notion of fuzzy uncertainty in the analysis. The generation of policy options and selection of evaluation criteria (step 3) are based on the information collected in step 2. Ideally, this should be a process of co-creation resulting from a dialogue between analysts and relevant social actors. Although the definition of the evaluation criteria is mainly the 
Refer to as: Diaz-Maurin, F.; Yu, J.; Ewing, R.C. Socio-technical multi-criteria evaluation of long-term spent nuclear fuel management strategies: A framework and method. Science of the Total Environment In press. Available at: 10.31223/X5459S.

task of the analysts, they should provide a technical translation of the social actors' needs, preferences and desires. The construction of the multi-criteria impact matrix (step 4) is, by far, the most data intensive step of a social multi-criteria evaluation process, especially when it deals with a broad range of dimensions of analysis (e.g., technical, economic, safety, environmental dimensions). The multi-criteria impact matrix synthesises the performance of each alternative according to each criterion. Then, the construction of a social impact matrix (step 5) allows one to complete the multi-criteria impact matrix based on the criteria, although the criterion scores (i.e., the expected outcome of each option are assigned a numerical score on a strength of preference scale for each criterion, generally extending from 0 to 100) are not determined directly by the social actors. The social impact matrix ensures that the technical translation, operationalized by the analysts in the multicriteria evaluation, is checked against an assessment of the social actors' preferences. Combining a technical multi-criteria impact (or evaluation) matrix with a social impact matrix is a desired property of a social multi-criteria evaluation process (Greco and Munda, 2017; Munda, 1995).

The next step applies a mathematical procedure (or algorithm) (step 6) that aggregates the criterion scores and generates a final ranking of the proposed alternatives. Many aggregation methods exist, each with its own advantages and disadvantages (Greco et al., 2016). Finally, the sensitivity and robustness analysis (step 7) seeks to look at the sensitivity of the ranking to the exclusion/inclusion of criteria, criterion weights and dimensions (Saltelli et al., 2008). Although this is mainly a technical step, it also includes a 
Refer to as: Diaz-Maurin, F.; Yu, J.; Ewing, R.C. Socio-technical multi-criteria evaluation of long-term spent nuclear fuel management strategies: A framework and method. Science of the Total Environment In press. Available at: 10.31223/X5459S.

social component, as the inclusion/exclusion of a given dimension, or set of criteria, reflects the social debate and deliberation among social actors (Greco and Munda, 2017).

Although Munda's approach is a step-wise process, it differs from other multicriteria frameworks that typically work iteratively towards a final (optimal) alternative. In the social multi-criteria evaluation approach, the iteration concerns the overall process by searching for compromise solutions once distributional conflicts between the technical performance and social impact have been highlighted by the analysis. In addition, the seven steps proposed by Munda are not fixed. Indeed, a central tenet of social multi-criteria evaluation is to allow flexibility and adaptability to the actual decision problem.

\section{B.2. Existing methods}

We now review the different existing multi-criteria analysis techniques and discuss their previous applications to the nuclear waste management decision problem. We focus on their relevance to nuclear waste management from a social conflict resolution perspective. A detailed review of existing multi-criteria analysis techniques is available from the UK Department for Communities and Local Government (2009).

Using a comprehensive bibliometric database of over 30,000 scientific articles about nuclear waste management published during the 1979-2017 period (Diaz-Maurin et al., 2019), we could identify only very few papers applying multi-criteria analysis techniques in this area. This can be explained by the fact that nuclear waste management is mainly the responsibility of governments that generally do not publish their methods and results in the scientific literature. 
Refer to as: Diaz-Maurin, F.; Yu, J.; Ewing, R.C. Socio-technical multi-criteria evaluation of long-term spent nuclear fuel management strategies: A framework and method. Science of the Total Environment In press. Available at: 10.31223/X5459S.

Formally, nuclear waste management can be considered as a discrete multi-criteria problem for which a finite number of feasible options is known — from storage at reactor sites, to interim storage at another site and/or to disposal in a deep geologic repository. A multi-criteria approach to nuclear waste management will thus consist in ranking these feasible options based on a set of evaluation criteria. An alternative approach could be to frame nuclear waste management as a continuous decision problem with multiple objectives at once and no clear way of deciding which one should be the objective function and the rest be represented as constraints (DCLG, 2009). The main objective of such approach, called multiple objective decision-making (MODM), thus is the search for efficient solutions. In practice, like with MAUT, this technique consists of maximizing the decision maker's overall goal (objective) as a function of the decision variables while this objective function is limited by the other functional constraints characterizing the operating environment. Yet, MODM methods, like standard MCDA techniques searching for optimal solutions, focus on the perspectives of the decision-makers; thus, they exclude from the analysis the concept of social actor that is crucial in nuclear waste management decision problems. We exclude continuous multi-criteria analysis methods. We also exclude from this review other standard multi-criteria analysis techniques, such as non-compensatory direct estimation methods and linear additive models, that do not address decision problems from a social conflict resolution perspective involving multiple actors. 
Refer to as: Diaz-Maurin, F.; Yu, J.; Ewing, R.C. Socio-technical multi-criteria evaluation of long-term spent nuclear fuel management strategies: A framework and method. Science of the Total Environment In press. Available at: 10.31223/X5459S.

\section{B.2.1. Discrete multi-criteria techniques}

Among the main techniques proposed to solve a discrete multi-criteria problem, the multi-attribute utility (or value) theory (MAUT) and outranking methods have been the most popular (Greco and Munda, 2017). MAUT methods seek to determine a utility (or value) function defined on the set of feasible alternatives and, then, to maximize this function (Keeney and Raiffa, 1976; Keeney and von Winterfeldt, 1994; Merkhofer and Keeney, 1987). To be operational, the function maximization in MAUT must assume the complete compensation of criteria and dimensions. The compensation assumption requires the method to resolve any trade-off appearing between non-equivalent dimensions of analysis. Yet, in practice, trade-offs between criteria and dimensions cannot be easily determined due to the unavoidable incommensurability of values and ambiguity of preferences, particularly across different social actors. In social decisions, trade-offs must rather be negotiated between social actors and, then, translated by the analysts. In its simplest and most common analytical form, MAUT uses a linear aggregation rule. Among the applications of MAUT, the analytic hierarchy process (AHP) developed by Saaty (1980) is the most popular. Concerns have been raised about the theoretical foundations of the AHP and some of its properties, especially regarding the problem of rank reversal. Rank reversal occurs when, by simply adding another option to the list of options being evaluated, the ranking of two other options, although unrelated to the new one, can be reversed (DCLG, 2009).

In contrast, outranking methods are based on the concept of partial comparability. Among the many methods available, ELECTRE (Roy, 1996) and PROMETHEE (Brans et 
Refer to as: Diaz-Maurin, F.; Yu, J.; Ewing, R.C. Socio-technical multi-criteria evaluation of long-term spent nuclear fuel management strategies: A framework and method. Science of the Total Environment In press. Available at: 10.31223/X5459S.

al., 1986) are the most commonly used. Outranking methods consist in comparing criteria by means of partial binary relations based on indexes of concordance/discordance and then to aggregate these relations (Greco and Munda, 2017). Several approaches exist to generate and treat outranking relations depending on the type of decision problem at hand.

Outranking methods also differ about the type of data inputs they can use; either quantitative, qualitative - precise or imprecise —or mixed data (DCLG, 2009). Among available outranking methods for environmental management and policy, the NAIADE method originally developed by Munda (1995) is of particular relevance to the nuclear waste management decision problem. NAIADE uses an impact matrix that may include crisp, stochastic or fuzzy measurements of the performance of an alternative with respect to an evaluation criterion (Greco and Munda, 2017). The STMCE approach presented in this paper extends the original NAIADE method (Munda, 1995) for the aggregation convention and Munda's more recent work (Munda, 2012) that introduces weights as importance coefficients both for criteria and social groups. The main issue with outranking methods concerns its dependence on the arbitrary definitions of what precisely constitutes outranking and how the threshold values are set can be manipulated by the decision makers (DCLG, 2009). To address this issue, the social multi-criteria evaluation process - and by extension the STMCE method presented in this paper-must include the participation of concerned social actors in the problem framing, the selection of alternatives, criteria and threshold values, as well as for the assessment of the social impact of each alternative. 
Refer to as: Diaz-Maurin, F.; Yu, J.; Ewing, R.C. Socio-technical multi-criteria evaluation of long-term spent nuclear fuel management strategies: A framework and method. Science of the Total Environment In press. Available at: 10.31223/X5459S.

\section{B.2.2. Previous applications}

We now discuss previous applications of discrete multi-criteria analysis methods to nuclear waste management issues in the United States and in other countries, as summarized in Table B.2.

Applications using MAUT methods

In 1982, Saaty published a study applying his newly developed AHP method to the comparison of different high-level nuclear waste disposal concepts proposed by the U.S. DOE (Saaty and Gholamnezhad, 1982). As this application was made from the sole perspective of the U.S. DOE, it allowed the analysts to assume the complete compensation of the performance of health, safety, and environmental impacts with costs and political considerations. Moreover, they also assigned weights to each disposal strategy considered in order to translate the priorities and preferences of DOE. The analysis concluded on geological disposal being the best alternative available over, in decreasing order of performance, space disposal, very deep borehole disposal, island disposal, and sub-seabed disposal. As deep, mined geologic repositories was considered by the scientific community as the best technical solution for the disposal of radioactive materials since the late $1950 \mathrm{~s}$ (National Research Council, 1957), it is not clear whether this application had any impact on the U.S. waste disposal strategy. This example shows that, to be effective, the MAUT approach requires that trade-offs can be decided upon internally. This may be the case of entrepreneurial or technocratic decisions for which a decision-maker can be clearly identified and will take responsibility for the decision outcome; but it will hardly be the 
Refer to as: Diaz-Maurin, F.; Yu, J.; Ewing, R.C. Socio-technical multi-criteria evaluation of long-term spent nuclear fuel management strategies: A framework and method. Science of the Total Environment In press. Available at: 10.31223/X5459S.

case in environmental management and public policy affected by social, political and legal conflicts, such as commercial spent fuel management in the United States.

A few years later, in 1985, with many sites under consideration for a geologic repository, the U.S. DOE performed a multi-attribute utility analysis (MUA) to rank sites (US DOE, 1986). DOE's MUA method was a direct application of the MAUT approach. After reviewing a draft of the MUA method, the National Research Council's Board on Radioactive Waste Management (BRWM) emphasized that the MUA methodology would be best applied only as a decision-aiding tool complemented by additional factors and judgements before making a final decision about what sites to characterize through a performance assessment (US NWTRB, 2015). The BRWM eventually considered the approach appropriate to integrate technical, economic, environmental, socioeconomic, and health and safety issues, despite stating that it had not reviewed the data and judgments on which the conclusions of the MUA would be based. A technical critique of DOE's MUA method was eventually published that listed limitations typical of multi-criteria analysis methods (Merkhofer and Keeney, 1987) and that Keeney and von Winterfeldt (1994) attempted to resolve in a refined MUA methodology.

Following the BRWM review, DOE then applied its proposed MUA method to compare five sites - three salt sites, the Hanford site in Washington state and the Yucca Mountain site in Nevada. These sites were evaluated against pre- and post-closure performance outcomes. After applying a composite aggregation, the MUA method ranked the Yucca Mountain site first, followed by the three salt sites, and then, lagging behind, by the Hanford site (US DOE, 1986). The Secretary of Energy then recommended President 
Refer to as: Diaz-Maurin, F.; Yu, J.; Ewing, R.C. Socio-technical multi-criteria evaluation of long-term spent nuclear fuel management strategies: A framework and method. Science of the Total Environment In press. Available at: 10.31223/X5459S.

Reagan to select three sites for in-depth characterization, including the Hanford site. Yet, as the debate moved to political and legal grounds, the Secretary recommendations were challenged in Congress. At one instance, a Committee investigation found that DOE had modified the weighting on the various components - effectively assigning low weighting to post-closure safety-which the Committee interpreted as supporting the selection of the Hanford site over the three salt sites. Members of Congress insisted that the decision to select a geologic repository shall be based on the soundest scientific and technical judgments possible, to which the DOE responded that the MUA method was by no means capable of providing "scientific evidence" that would somehow be devoid of "judgment" (US NWTRB, 2015). In this view, DOE did not have to necessarily select the top-ranked sites identified by the MUA.

The multi-attribute evaluation process carried out by DOE in 1985-86 was only a step in a lengthy site selection process that, as it turned out, was subsequently replaced by the 1987 Nuclear Waste Policy Act Amendments, which narrowed the scope of DOE's investigation to a single site, Yucca Mountain in Nevada. Yet, it reveals the different possible interpretations about the role of a multi-criteria analysis in a decision-making process. This example illustrates the importance of being explicit—and transparent—about the purpose of a multi-criteria analysis rather than focusing on developing a sophisticated method.

More recently, Sandia National Laboratories and Argonne National Laboratory compiled a comprehensive initial set of potential nuclear waste management system attributes (Kalinina and Samsa, 2016). This work sought to prepare the development of a 
Refer to as: Diaz-Maurin, F.; Yu, J.; Ewing, R.C. Socio-technical multi-criteria evaluation of long-term spent nuclear fuel management strategies: A framework and method. Science of the Total Environment In press. Available at: 10.31223/X5459S.

waste management system multi-objective evaluation framework (MOEF) based on the MUA approach. Using inputs from past studies that involved the participation of various external stakeholders, this work defined over 130 attributes organized in a hierarchal structure. As of writing, it is not clear whether DOE and the national laboratories are pursuing their effort to develop the MOEF system. However, given MOEF is sought to help inform policy options and system analysis scenarios at the national level, it is not clear how, in practice, it would include the participation of stakeholders at this level; especially how it would deal with stakeholders' differing goals and perspectives in a framework that searches for the maximization of one overall utility function.

\section{Applications using outranking methods}

In the 1990s, with the development of outranking methods in Europe, the PROMETHEE and ORESTE methods were applied to nuclear waste management. The first application by Briggs and colleagues (1990) treated the full nuclear waste management process (interim storage, transport and geologic disposal) for all types of radioactive waste materials (LLW/ILW, HLW and SNF). However, the method focused only on the financing methods as a mean to rank sites, without an assessment of their technical suitability. Moreover, because PROMETHEE methods are based on a complete compensation assumption (Table B.1), the authors acknowledged that different alternatives could only be assessed against a small number of strongly conflicting criteria, because otherwise too many trade-offs would be introduced in the analysis. In a second application, Delhaye and co-workers (1991) proposed the ORESTE method as an alternative to PROMETHEE but it 
Refer to as: Diaz-Maurin, F.; Yu, J.; Ewing, R.C. Socio-technical multi-criteria evaluation of long-term spent nuclear fuel management strategies: A framework and method. Science of the Total Environment In press. Available at: 10.31223/X5459S.

is essentially the same as the first application (both papers have one author in common) and focuses on the financing of nuclear waste management options. The third application by Petraš (1997) focused on the selection of sites for the surface disposal facilities of low- and intermediate-level nuclear waste (LLW/ILW); hence it does not include interim storage and geologic disposal. As LLW and ILW represent larger volumes as compared with high-level waste (HLW) and spent nuclear fuel (SNF), the study was performed from a land use management perspective; hence not from a social conflict resolution approach.

\section{Applications using other methods}

In their conceptual study, Atherton and French (1998) proposed a discounted utility theory (DUT) approach as a way to address long-term nuclear waste management. The DUT method is a normative discounting model to account for the value of the decision maker's relationship to the different time frames. Such approach that deals with multiple time periods thus seems particularly relevant to nuclear waste management requiring to make decisions with consequences over long periods of time-from decades for interim storage to thousands of years for geologic disposal. However, the major problem with this approach is that it is impossible — at least very difficult — to make a judgement about the values of future generations and, especially, how to deal with the trade-offs between present values and future outcomes. This approach, that focuses on maximizing utility, thus faces issues of inter- and intra-generational ethics about how to treat technological risk and duties to future generations (Shrader-Frechette, 2000). 
Refer to as: Diaz-Maurin, F.; Yu, J.; Ewing, R.C. Socio-technical multi-criteria evaluation of long-term spent nuclear fuel management strategies: A framework and method. Science of the Total Environment In press. Available at: 10.31223/X5459S.

More recently, Morton and colleagues (2009) reviewed the multi-criteria decision analysis of different management options by the UK's Committee on radioactive waste management (CoRWM). In the process of defining its MCDA method, CoRWM found itself focusing on the trade-off between flexibility and burden of ongoing maintenance of storage. This trade-off between short-term and long-term objectives is a common issue in nuclear waste management. Yet, in the case of CoRWM, it is unclear whether and how it resolved the problem of trade-offs - a crucial issue for any MCDA. As it appears, the CoRWM decision analysis experience, so far, focused on discussing the role option assessment using MCDA approach should have in decision process, but did not get to the point of applying or developing such methods (Morton et al., 2009).

In parallel, $\mathrm{Xu}$ (2009) proposed a different method that is based on the evidential reasoning (ER) decision approach to assess two potential repository options for low- and medium-level short-lived waste in Belgium. Yet, like MAUT methods, the ER decision approach searches for the maximization of a utility function for each criterion and then performs a linear weighted aggregation of these functions. As such, the ER approach implies a total linear compensation among criteria that is not a desirable property in social multi-criteria evaluation (Table B.1).

Finally, most recently, Schwenk-Ferrero and Andrianov (2017) proposed a MCDA framework for the comparison of nuclear waste management strategies based on a hierarchical objective structure. The authors reviewed different MCDA methods (such as MAVT/MAUT, AHP, TOPSIS, PROMETHEE) and selected the MAVT approach as their reference method for their application thus applying weights as tradeoffs between the 
Refer to as: Diaz-Maurin, F.; Yu, J.; Ewing, R.C. Socio-technical multi-criteria evaluation of long-term spent nuclear fuel management strategies: A framework and method. Science of the Total Environment In press. Available at: 10.31223/X5459S.

criteria. As explained, MAVT is not an appropriate approach for the comparison of nuclear waste management strategies from a social multi-criteria evaluation perspective.

\section{B.3. Method description}

\section{B.3.1. Socio-technical approach to spent fuel management}

Spent nuclear fuel management decisions require going through two types of filters: technical filters and social filters (Metlay and Ewing, 2014; US NWTRB, 2015). This is explained by the need to site facilities, such as geologic repositories for disposal and interim facilities for storage, that must be both technically sound and socially accepted. In a decision process, it does not matter which one of the technical or social filters is met first as long as both are satisfied. Yet, the two technical and social dimensions are interdependent (Diaz-Maurin and Ewing, 2018; US NWTRB, 2015). For instance, solutions for which the technical suitability can be demonstrated by relatively simple analyses may increase social acceptance; whereas, in site selection processes, specific site-suitability criteria are often added to account for the views of the public, thus, ultimately providing a societal content to the definition of technical suitability. In another example, the hypothesis by the U.S. National Academy of Sciences of a fundamental geologic regime remaining stable up to about one million years was used as a technical basis for introducing the one-million-year compliance period in the Yucca Mountain standards; thus responding to the societal demands for a longer regulatory period in the long-term safety demonstration (National Research Council, 1995). 
Refer to as: Diaz-Maurin, F.; Yu, J.; Ewing, R.C. Socio-technical multi-criteria evaluation of long-term spent nuclear fuel management strategies: A framework and method. Science of the Total Environment In press. Available at: 10.31223/X5459S.

The STMCE method goes beyond this process by performing several multi-criteria evaluations according to technical and societal dimensions of analysis - and their combination. This allows one to highlight potential performance gaps between the technical and societal dimensions through the multi-criteria evaluation of options. In addition, potential conflicts between the preferences of the concerned actors are highlighted by the social impact analysis that translates the perceived impact of each option for each social actor.

\section{B.3.2. Multi-criteria evaluation procedure}

\section{Aggregation convention}

The socio-technical multi-criteria evaluation method consists of three complementary evaluations based on (1) a set of technical criteria, (2) a set of societal criteria, and (3) their combination. Each one of the multi-criteria evaluations is based on the same aggregation convention. We adapted the aggregation convention originally developed by Munda $(2012,2008)$. The multi-criteria evaluation consists of (1) the pairwise comparison of alternatives according to a set of criteria, and (2) the generation of an ordinal ranking of alternatives using the aggregated criterion scores.

Formally, let us consider a set of evaluation criteria $G=g_{m}, m=1,2, \ldots, M$, and a finite set $A=a_{n}, n=1,2, \ldots, N$ of potential alternatives (options). Let us now start with the simple assumption that the performance (i.e., the criterion score) of an alternative $a_{n}$ with respect to a judgement criterion $g_{m}$ is based on an interval or ratio scale of measurement. 
Refer to as: Diaz-Maurin, F.; Yu, J.; Ewing, R.C. Socio-technical multi-criteria evaluation of long-term spent nuclear fuel management strategies: A framework and method. Science of the Total Environment In press. Available at: 10.31223/X5459S.

In order to rank alternatives, let us introduce an indifference threshold that indicates the degree of difference up to which two options are considered equivalent and, consequently, the degree of difference from which a preference relation exists. By defining a positive indifference threshold $q$, we can now define the resulting threshold model as:

$$
\left\{\begin{array}{l}
a_{j} P a_{k} \Leftrightarrow g_{m}\left(a_{j}\right)>g_{m}\left(a_{k}\right)+q \\
a_{j} I a_{k} \Leftrightarrow\left|g_{m}\left(a_{j}\right)-g_{m}\left(a_{k}\right)\right| \leq q
\end{array}\right.
$$

where $a_{j}$ and $a_{k}$ belong to the set $A$ of alternatives and $g_{m}$ to the set $G$ of evaluation criteria.

In the threshold model, $a_{j} P a_{k}$ means that alternative $j$ is preferred over alternative $k$ if the difference in the criterion scores between the two alternatives is greater than the indifference threshold $q$. Otherwise, the difference between the criterion scores is considered to be not significant and there is no preference between the two alternatives (i.e., $\left.a_{j} I a_{k}\right)$.

Based on these indifference and preference relations between two alternatives, we can now construct an outranking matrix $E \in \mathbb{R}^{M \times M}$ as:

$$
e_{j k}=\sum_{m=1}^{M}\left(w_{m}\left(P_{j k}\right)+\frac{1}{2} w_{m}\left(I_{j k}\right)\right)
$$

where $w_{m}$ belongs to a set of weights $W=w_{m}, m=1,2, \ldots, M$ that can serve as importance coefficients of the set of evaluation criteria $G$. However, in the analysis all the criteria are considered to have the same importance, so that no weighting coefficient is used (i.e., $w_{m}=\frac{1}{M}$ and $\sum_{m=1}^{M} w_{m}=1$ ). By construction, it follows that $e_{j k}+e_{k j}=1$. 
Refer to as: Diaz-Maurin, F.; Yu, J.; Ewing, R.C. Socio-technical multi-criteria evaluation of long-term spent nuclear fuel management strategies: A framework and method. Science of the Total Environment In press. Available at: 10.31223/X5459S.

The aggregated score $r_{j}$ for a given alternative $j$ is obtained by taking the sum of all the row entries in the outranking matrix $E$ as:

$$
r_{j}=\sum_{k} e_{j k}
$$

The ranking of a given alternative $j$ can then be determined by the order of $r_{j}$ in the set of aggregated scores $R=r_{n}, n=1,2, \ldots, N$. The alternative with the highest aggregated score will be ranked first.

\section{Monte Carlo simulation}

A sensitivity and robustness analysis is used to generate the distribution of the possible rankings considering stochastic uncertainty on the criteria scores. For this, we use a Monte Carlo simulation to repeatedly run the multi-criteria evaluation based on randomly generated samples of criteria scores. This method allows us to determine the most likely ranking of alternatives, given a range of values for the criterion scores.

For each Monte Carlo simulation, each criterion score is sampled from some unknown distribution, where the only known values are the score's mean, minimum, and maximum. We assume that all criterion scores are normally distributed. While the mean for each distribution is known, the standard deviation is not given and must be estimated. We apply the "Three-Sigma Rule" that states that approximately $99.73 \%$ of all values of a normally distributed parameter fall within three standard deviations of the mean (Duncan, 2000). We can thus estimate the standard deviation as:

$$
\sigma=\frac{H C V-L C V}{6}
$$


Refer to as: Diaz-Maurin, F.; Yu, J.; Ewing, R.C. Socio-technical multi-criteria evaluation of long-term spent nuclear fuel management strategies: A framework and method. Science of the Total Environment In press. Available at: 10.31223/X5459S.

where $H C V$ (Highest Conceivable Value) and $L C V$ (Lowest Conceivable Value) represent the maximum and minimum values provided for the criterion score, respectively.

To formalize the Monte Carlo sampling, let $C$ be the set of criterion scores. Let then $x_{i}, \mu_{i}, L C V_{i}, H C V_{i}$ be the sampled value, mean, minimum, and maximum for criterion score $i \in C$, respectively. We can thus define the percentage deviation from the mean of the sampled value $x_{i}$ as:

$$
d_{i}= \begin{cases}\frac{\left|x_{i}-\mu_{i}\right|}{\left|\mu_{i}-L C V_{i}\right|} & \text { if }\left|x_{i}-\mu_{i}\right|<0 \\ \frac{\left|x_{i}-\mu_{i}\right|}{\left|\mu_{i}-H C V_{i}\right|} & \text { else }\end{cases}
$$

The procedure can also conduct post-sampling adjustments on the sampled values of criteria in two cases. First, when a normal distribution cannot be considered because the criterion values are fixed ("either/or" condition), the randomly generated values are set to the closest known values (mean, minimum or maximum). Second, when criteria correlated with one another, we consider the value sampled from one score's distribution to be conditional on the value obtained from a correlated score's distribution. We consider only linear correlations (direct or inverse) controlled by linear adjustment to the sampled values of correlated criteria.

Formally, the post-sampling adjustment for criterion score $i$ is equal to the sum of deviations from its correlated criterion scores. Let $J_{i}=j: \operatorname{corr}(i, j) \neq 0 ; i, j \in C$ be the criterion scores that are correlated with $i$. The post-sampling adjustment is defined as $\operatorname{adj}_{i}=\sum_{j \in J} d_{j}$. We can now define the final value after post-sampling adjustment as: 
Refer to as: Diaz-Maurin, F.; Yu, J.; Ewing, R.C. Socio-technical multi-criteria evaluation of long-term spent nuclear fuel management strategies: A framework and method. Science of the Total Environment In press. Available at: 10.31223/X5459S.

$$
x_{i, \text { adj }}= \begin{cases}x_{i}+\operatorname{adj}_{i}\left|\mu_{i}-L C V_{i}\right| & \text { ifadj }_{i}<0 \\ x_{i}+\operatorname{adj}_{i}\left|\mu_{i}-H C V_{i}\right| & \text { else }\end{cases}
$$

We thus obtain a set $C^{\prime}$ of randomly sampled and adjusted criterion scores that can be used in the multi-criteria evaluation.

We conduct the Monte Carlo sampling in R (R Core Team, 2019) using the function set. seed that can reproduce the same sequence. That is, the runif function in $R$ does not involve randomness per se, but is a deterministic sequence based on a random starting point. For instance, the seed number "2020" always returns the following sequence for the first four random variables:

$>$ set.seed (2020)

$>\operatorname{runif}(4)$

[1] $0.6469028 \quad 0.3942258 \quad 0.6185018 \quad 0.4768911$

Each multi-criteria evaluation is thus performed $n$ times, where $n$ is the number of random samples of criteria scores required to obtain computational convergence of the rankings. The number of Monte Carlo random samples is determined empirically.

\section{B.3.3. Social impact and conflict analysis}

Fuzzy cluster analysis

To contrast the results of the multi-criteria evaluation, we perform an analysis of the social impact of the alternatives on the interests of the social actors. For this, we adapted 
Refer to as: Diaz-Maurin, F.; Yu, J.; Ewing, R.C. Socio-technical multi-criteria evaluation of long-term spent nuclear fuel management strategies: A framework and method. Science of the Total Environment In press. Available at: 10.31223/X5459S.

the same framework as proposed by Munda $(2008,1995)$. The impact of each alternative on each social actor is evaluated by the analysts based on their assessment of how they are impacted. This step can be done by reviewing available material and eventually by asking opinions through focus groups, interviews or questionnaires. The impacts are recorded by means of seven linguistic variables: "Very bad", "Bad", "More or less bad", "Moderate", "More or less good", "Good", and "Very good". Formally, let $X$ represent the set of possible impacts. With this, we can obtain a social impact matrix $S \in X^{P \times N}$, where $P$ is the number of social actors and $N$ is the number of alternatives.

To make comparisons between linguistic variables, we compute their semantic distances using fuzzy sets. Fuzzy sets are based on the idea of introducing a degree of membership of an element with respect to some sets (Munda, 1995). Fuzzy sets are necessary in order to introduce some level of uncertainty within linguistic variables. That is, the measurement scale based on linguistic variables is not purely ordinal. Fuzzy uncertainty refers to the degree of ambiguity in the information about the system that generates fuzziness in the evaluation of the impact of alternatives on the social actors' interests. Specifically, a semantic rule $M$ is used to associate a linguistic variable with its meaning and incorporates a compatibility (membership) function $\mu: X \rightarrow[0,1]$ to represent the degree of membership. For instance, $\mu_{\text {good }}$ shows the degree to which a numerical score is compatible with the concept of good and equivalently $\mu_{\text {good }}$ may be viewed as the membership function of the fuzzy set good. Fig. B.2 shows the membership functions defining the fuzzy set for the seven linguistic variables used. 
Refer to as: Diaz-Maurin, F.; Yu, J.; Ewing, R.C. Socio-technical multi-criteria evaluation of long-term spent nuclear fuel management strategies: A framework and method. Science of the Total Environment In press. Available at: 10.31223/X5459S.

We then use the semantic distance $S_{d}$ between any pair of social actors as a conflict indicator (Munda, 2009). Let $\mu_{1}$ and $\mu_{2}$ be membership functions. Let $f(x)=k_{1} \mu_{1}(x)$ and $g(y)=k_{2} \mu_{2}(x)$, where $k_{1}$ and $k_{2}$ are constants obtained by rescaling $\mu_{1}$ and $\mu_{2}$, respectively, such that:

$$
\int_{-\infty}^{+\infty} f(x) d x=\int_{-\infty}^{+\infty} g(y) d y=1
$$

Furthermore, $f(x) \in X=\left[x_{L}, x_{U}\right]$ and $g(y) \in Y=\left[y_{L}, y_{U}\right] . S_{d}$ is then defined as:

$$
S_{d}(f(x), g(y))=\iint_{x, y}|x-y| f(x) g(y) d y d x
$$

In the case when the intersection of the two membership functions is empty, we have:

$$
S_{d}(f(x), g(y))=|E(x)-E(y)|
$$

where $E(x)$ and $E(y)$ are the expected values of the two membership functions.

When the intersection between the two fuzzy sets is non-empty, their semantic distance is actually computationally intractable by means of iterated integration (Munda, 1995). Thus, we use a Monte Carlo type numerical procedure as in Munda (1995). The procedure is as follows:

Algorithm 1: Numerical procedure to compute semantic distance

1. Draw a random number $r_{0}\left(0 \leq r_{0} \leq 1\right)$

2. $x_{1}=r_{0} x_{L}+\left(1-r_{0}\right) x_{U}$

3. Draw a random number $z_{0}\left(0 \leq z_{0} \leq \max f(x)\right)$

4. If $z_{0}>f\left(x_{1}\right)$ return to step 1; else move to next step 
Refer to as: Diaz-Maurin, F.; Yu, J.; Ewing, R.C. Socio-technical multi-criteria evaluation of long-term spent nuclear fuel management strategies: A framework and method. Science of the Total Environment In press. Available at: 10.31223/X5459S.

5. Draw a random number $r_{1}\left(0 \leq r_{1} \leq 1\right)$

6. $y_{1}=r_{1} y_{L}+\left(1-r_{1}\right) y_{U}$

7. Draw a random number $z_{1}\left(0 \leq z_{1} \leq \max g(y)\right)$

8. If $z_{1} \leq g\left(y_{1}\right)$ compute $\left|x_{1}-y_{1}\right|$; else return to step 5

This procedure is repeated $n=1000$ times, and the mean of all the computed terms is approximately equal to the distance between the two fuzzy sets. That is:

$$
S_{d}(f(x), g(y)) \approx \frac{1}{n} \sum_{i=1}^{n}\left|x_{i}-y_{i}\right|
$$

In the analysis, a generalization of the Minkowski p-metric with a Euclidean value metric $p=2$ (partial compensation) is applied (Munda, 2009). That is:

$$
S_{d}(f(x), g(y)) \approx \frac{1}{n}\left(\sum_{i=1}^{n}\left|x_{i}-y_{i}\right|^{2}\right)^{1 / 2}
$$

By using the semantic distance described in Eq. (9) and (11) as a conflict indicator of the preferences among the social actors, we construct a similarity matrix for all possible pairs of actors. The similarity matrix $s \in[0,1]^{P \times P}$, where $P$ is the number of social actors, is constructed by means of a simple transformation as:

$$
s_{i j}=\frac{1}{1+d_{i j}}, 1 \leq i, j \leq P
$$

From the similarity matrix, we can then create a dendrogram to visualize the level of similarity between the social actors based on their expressed option preferences. This 
Refer to as: Diaz-Maurin, F.; Yu, J.; Ewing, R.C. Socio-technical multi-criteria evaluation of long-term spent nuclear fuel management strategies: A framework and method. Science of the Total Environment In press. Available at: 10.31223/X5459S.

allows the social actors to learn the extent to which they agree on their preferences over different alternatives. For this, a fuzzy cluster algorithm can be used that synthesizes similarities/diversities among social actors (Munda, 2009).

To generate the dendrogram, we use the hclust function that is the default hierarchical clustering method in R ( $\mathrm{R}$ Core Team, 2019). This clustering method defines the distance between two clusters to be the maximum distance between their individual components. The hierarchical clustering process consists in making pair-wise comparisons of all elements of the similarity matrix $s$. At every step of the clustering process, the two nearest clusters are merged into a new cluster. The process is repeated until the whole data set is agglomerated into one single cluster.

\section{Ranking alternatives}

We can now combine the weights obtained for the social actors with the social impact matrix $S$, that represents each actor's perceived impact from the alternatives. Like in section B.3.2, we first build an outranking matrix $E \in \mathbb{R}^{N \times N}$ as:

$$
e_{j k}=\sum_{p=1}^{P}\left(\lambda_{p}\left(P_{j k}\right)+\frac{1}{2} \lambda_{p}\left(I_{j k}\right)\right)
$$

where a vector $\Lambda$ of weights is attached to the set of the $P$ social actors, indicating

their relative importance, so that: $\Lambda=\left\{\lambda_{p}\right\}, \mathrm{p}=1,2, \ldots, \mathrm{P}$, with $\sum_{p=1}^{P} \lambda_{p}=1$. In this framework, we consider an equal weighting assumption of actors $\left(\lambda_{p}=1,, \mathrm{p}=1,2, \ldots, \mathrm{P}\right)$. We provide in the next section a possible procedure to attribute weights as importance coefficients to the various social actors. 
Refer to as: Diaz-Maurin, F.; Yu, J.; Ewing, R.C. Socio-technical multi-criteria evaluation of long-term spent nuclear fuel management strategies: A framework and method. Science of the Total Environment In press. Available at: 10.31223/X5459S.

Again, to get the ranking of alternatives, we simply take the sum of all the row entries for a given alternative in the outranking matrix to get an aggregate score. For a given alternative $j$, the aggregated score $r_{j}=\sum_{k} e_{j k}$. The ranking is then determined by the order of the aggregate scores.

The process described above is similarly performed for the $K$ coalitions formed by the dendrogram. The coalitions are extracted from the dendrogram using the cutree function in $\mathrm{R}$. The number of coalitions $K$ is determined by the user after inspecting the results of the dendrogram. So, in addition to the ranking of alternatives for all social actors, $K$ rankings are similarly made for each coalition.

Last, we also calculate the number of options that a coalition can veto for all $K$ coalitions. Here, we wish to identify the options that are considered "very bad" by certain groups so that we can better identify the stable solutions. We follow Moulin's (1981) theorem, which says that any group with $x$ percent of social actors has the ability to veto up to $x$ percent of alternatives. This takes the form of a proportional veto function, which is defined as (Munda, 2009):

$$
V_{P, N}\left(c_{i}\right)=\left(N \cdot \frac{\left|c_{i}\right|}{P}\right)-1
$$

where $(x)$ is the largest integer bounded below by $x$. Recall that $P$ is the number of social actors, $N$ is the number of alternatives, and $c_{i}$ is the $i$ 'th group out of the $K$ coalitions. 
Refer to as: Diaz-Maurin, F.; Yu, J.; Ewing, R.C. Socio-technical multi-criteria evaluation of long-term spent nuclear fuel management strategies: A framework and method. Science of the Total Environment In press. Available at: 10.31223/X5459S.

\section{Weighting actors in the STMCE approach}

Any weighting of social groups requires a normative justification (Munda, 2008).

STMCE uses an equal weighting assumption between criteria and dimensions. Because different dimensions are associated with different groups in society (Munda, 2008), if the selected criteria maximize exhaustiveness and minimize redundancy, then the equal weighting assumption is justified. However, when ranking alternatives based on the social impacts one must consider that not all social actors have the same levels of interest and influence in the decision problem, independently from how they may be impacted by each alternative. The weighting of social actors can thus be justified by the need to apply some type of importance/relevance coefficient to the concerned social actors, so that not all the impact evaluations will be treated equally in the ranking - contrary to the fuzzy cluster analysis.

Munda (2009) attributed weights as importance coefficients to the various social actors. Formally, a vector $\Lambda$ of weights is attached to the set of the $P$ social actors, indicating their relative importance: $\Lambda=\left\{\lambda_{p}\right\}, \mathrm{p}=1,2, \ldots, \mathrm{P}$, with $\sum_{p=1}^{P} \lambda_{p}=1$. Yet, in this approach, even if weights are introduced as importance coefficients, the vector $\Lambda$ is defined $a d$ hoc by the analyst and, thus, can be contested by the concerned parties. In the STMCE method, we use another approach to attribute weights to the social actors using an explicit method to extract their relative importance, that is, based on the assessment of their relative level of stakes.

In strategic management, power (or influence) refers to the ability of individuals or groups to persuade, induce or coerce others into following certain courses of action; 
Refer to as: Diaz-Maurin, F.; Yu, J.; Ewing, R.C. Socio-technical multi-criteria evaluation of long-term spent nuclear fuel management strategies: A framework and method. Science of the Total Environment In press. Available at: 10.31223/X5459S.

whereas interest (or stake) refers to ownership, right, wealth, benefit, risk, or any other tangible or intangible aspects that a given stakeholder considers as relevant and potentially affected, positively or negatively, by a given issue or decision (Johnson et al., 2008). We use a power/interest matrix of the social actors as a mean to generate weights. A power/interest matrix (also called "stakeholder map") is a 2-dimensional plot in which social actors are positioned according to their estimated level of power and interest (Olander and Landin, 2005). In the power/interest matrix, the x-axis represents the level of influence (power) the actor has on the decision and the y-axis represents the actor's level of interest (stakes) in the impact of that decision; the range of both axes is $[0,1]$. The power/interest matrix provides an intuitive way of positioning the social actors relatively to each other, allowing the analysts to obtain a natural and explicit weighting system. To avoid the issue of having to compensate power and interest (that are incommensurate), we consider weights only in relation the relative levels of interest (stakes) between actors ( $\mathrm{x}$ axis). Our weighting system is thus derived from the relative positions of actors along the $\mathrm{x}$-axis of the power/interest matrix.

Formally, the weighting system for the social actors is as follows:

1. We start with measuring the level of interest from the power/interest matrix. Let $z \in \mathbb{R}^{P}$, where $P$ is the number of social actors, be a vector that captures this information.

2. We calculate a distance matrix $D \in \mathbb{R}^{P \times P}$, where $D_{i j}=z_{i}-z_{j}$. That is, we obtain a matrix of the relative distances in interest level between the different social actors. 
Refer to as: Diaz-Maurin, F.; Yu, J.; Ewing, R.C. Socio-technical multi-criteria evaluation of long-term spent nuclear fuel management strategies: A framework and method. Science of the Total Environment In press. Available at: 10.31223/X5459S.

3. We then average the relative distances for each social actor in relation to the others as: $r_{p}=\frac{1}{m} \sum_{j} D_{i j},-1 \leq r_{p} \leq 1$.

4. Finally, we obtain the weight of the social actor as: $\lambda_{p}=1+r_{p}, 0 \leq \lambda_{p} \leq 2$.

One can confirm that the average weight of the social actors is $\frac{1}{P} \sum_{p} \lambda_{p}=1$. A value of $r_{p}=0$ would imply an equal weighting assumption (i.e., $\left.\lambda_{p}=1\right)$. The weighting system consists in applying a deviation around this value.

This weighting system can improve the social impact analysis by giving a degree of importance to social actors based on their estimated relative level of stakes in the decision problem and independently from how they may be impacted by each alternative. However, it requires the construction of a power/interest matrix of all actors for which estimated levels of interest may be affected by ambiguity and disagreement. An alternative weighting system can consist in estimating the stakes of each social actors by means of linguistic variables and treated as a fuzzy set, like for estimating the impacts of each alternatives. 
Refer to as: Diaz-Maurin, F.; Yu, J.; Ewing, R.C. Socio-technical multi-criteria evaluation of long-term spent nuclear fuel management strategies: A framework and method. Science of the Total Environment In press. Available at: 10.31223/X5459S.

\section{References}

Atherton, E., French, S., 1998. Valuing the future: a MADA example involving nuclear waste storage. Journal of Multi-Criteria Decision Analysis 7, 304-321. https://doi.org/10.1002/(SICI)1099-1360(199811)7:6<304::AIDMCDA225>3.0.CO;2-0

Bijker, W.E., Hughes, T.P., Pinch, T. (Eds.), 2012. The Social Construction of Technological Systems, Anniversary Edition. MIT Press, Cambridge, MA.

Brans, J.P., Vincke, Ph., Mareschal, B., 1986. How to select and how to rank projects: The PROMETHEE method. European Journal of Operational Research, Mathematical Programming Multiple Criteria Decision Making 24, 228-238. https://doi.org/10.1016/0377-2217(86)90044-5

Briggs, Th., Kunsch, P.L., Mareschal, B., 1990. Nuclear waste management: An application of the multicriteria PROMETHEE methods. European Journal of Operational Research 44, 1-10. https://doi.org/10.1016/0377-2217(90)90308-X

DCLG, 2009. Multi-criteria analysis: a manual. UK Department for Communities and Local Government, London, UK.

Delhaye, C., Teghem, J., Kunsch, P., 1991. Application of the ORESTE method to a nuclear waste management problem. International Journal of Production Economics 24, 29-39. https://doi.org/10.1016/0925-5273(91)90150-R

Diaz-Maurin, F., Ewing, R.C., 2018. Mission Impossible? Socio-Technical Integration of Nuclear Waste Geological Disposal Systems. Sustainability 10, 4390. https://doi.org/10.3390/su10124390

Diaz-Maurin, F., Sun, H.C., Yu, J., Ewing, R.C., 2019. Evolution and Structure of the Scientific Basis for Nuclear Waste Management. MRS Advances 4, 959-964. https://doi.org/10.1557/adv.2018.636

Doumpos, M., Figueira, J.R., Greco, S., Zopounidis, C. (Eds.), 2019. New Perspectives in Multiple Criteria Decision Making: Innovative Applications and Case Studies, Multiple Criteria Decision Making. Springer International Publishing, Cham, Switzerland. https://doi.org/10.1007/978-3-030-11482-4_11

Duncan, J.M., 2000. Factors of Safety and Reliability in Geotechnical Engineering. Journal of Geotechnical and Geoenvironmental Engineering 126, 307-316. https://doi.org/10.1061/(ASCE)1090-0241(2000)126:4(307)

Gass, S.I., 1983. Feature Article-Decision-Aiding Models: Validation, Assessment, and Related Issues for Policy Analysis. Operations Research 31, 603-631. https://doi.org/10.1287/opre.31.4.603

Greco, S., Ehrgott, M., Figueira, J.R. (Eds.), 2016. Multiple Criteria Decision Analysis: State of the Art Surveys, 2nd ed, International Series in Operations Research \& Management Science. Springer, New York, NY. https://doi.org/10.1007/978-14939-3094-4_27

Greco, S., Munda, G., 2017. Multiple criteria evaluation in environmental policy analysis, in: Spash, C.L. (Ed.), Routledge Handbook of Ecological Economics. Routledge, pp. 311-320. 
Refer to as: Diaz-Maurin, F.; Yu, J.; Ewing, R.C. Socio-technical multi-criteria evaluation of long-term spent nuclear fuel management strategies: A framework and method. Science of the Total Environment In press. Available at: 10.31223/X5459S.

Hillier, F.S., Lieberman, G.J., 2015. Introduction to Operations Research, 10th ed. McGraw-Hill Education.

Jasanoff, S., 2006. States of knowledge: the co-production of science and the social order, 1 st ed. Routledge.

Johnson, G., Scholes, K., Whittington, R., 2008. Exploring corporate strategy, 8th ed. Financial Times Prentice Hall, Essex, England, UK.

Kalinina, E., Samsa, M., 2016. A Literature Review and Compilation of Nuclear Waste Management System Attributes for Use in Multi-Objective System Evaluations 16618. Presented at the WM2016: 42. Annual Waste Management Symposium, 610 Mar 2016, WM Symposia, Inc., Phoenix, AZ, USA.

Keeney, R.L., Raiffa, H., 1976. Decisions with multiple objectives: preferences and value trade-offs. Wiley New York.

Keeney, R.L., von Winterfeldt, D., 1994. Managing Nuclear Waste from Power Plants. Risk Analysis 14, 107-130. https://doi.org/10.1111/j.1539-6924.1994.tb00033.x

Merkhofer, M.W., Keeney, R.L., 1987. A Multiattribute Utility Analysis of Alternative Sites for the Disposal of Nuclear Waste. Risk Analysis 7, 173-194. https://doi.org/10.1111/j.1539-6924.1987.tb00981.x

Metlay, D., Ewing, R., 2014. Safety Cases and Siting Processes, in: The Safety Case for Deep Geological Disposal of Radioactive Waste: 2013 State of the Art, Symposium Proceedings. OECD Publishing, Paris, France, pp. 319--324.

Morton, A., Airoldi, M., Phillips, L.D., 2009. Nuclear Risk Management on Stage: A Decision Analysis Perspective on the UK's Committee on Radioactive Waste Management. Risk Analysis 29, 764-779. https://doi.org/10.1111/j.15396924.2008.01192.x

Moulin, H., 1981. The Proportional Veto Principle. The Review of Economic Studies 48, 407-416. https://doi.org/10.2307/2297154

Munda, G., 2019. Multi-criteria Evaluation in Public Economics and Policy, in: Doumpos, M., Figueira, J.R., Greco, S., Zopounidis, C. (Eds.), New Perspectives in Multiple Criteria Decision Making: Innovative Applications and Case Studies, Multiple Criteria Decision Making. Springer International Publishing, Cham, Switzerland, pp. 297-313. https://doi.org/10.1007/978-3-030-11482-4_11

Munda, G., 2012. Intensity of preference and related uncertainty in non-compensatory aggregation rules. Theory Decis 73, 649-669. https://doi.org/10.1007/s11238-0129317-4

Munda, G., 2009. A conflict analysis approach for illuminating distributional issues in sustainability policy. European Journal of Operational Research 194, 307-322. https://doi.org/10.1016/j.ejor.2007.11.061

Munda, G., 2008. Social Multi-Criteria Evaluation for a Sustainable Economy. Springer Berlin Heidelberg, Berlin, Heidelberg.

Munda, G., 2004. Social multi-criteria evaluation: Methodological foundations and operational consequences. European Journal of Operational Research 158, 662-677. https://doi.org/10.1016/S0377-2217(03)00369-2 
Refer to as: Diaz-Maurin, F.; Yu, J.; Ewing, R.C. Socio-technical multi-criteria evaluation of long-term spent nuclear fuel management strategies: A framework and method. Science of the Total Environment In press. Available at: 10.31223/X5459S.

Munda, G., 1995. Multicriteria Evaluation in a Fuzzy Environment: Theory and Applications in Ecological Economics, Contributions to Economics. Physica-Verlag Heidelberg.

National Research Council, 1995. Technical Bases for Yucca Mountain Standards. The National Academies Press, Washington, DC. https://doi.org/10.17226/4943

National Research Council, 1957. The Disposal of Radioactive Waste on Land. The National Academies Press, Washington, DC. https://doi.org/10.17226/2345

Olander, S., Landin, A., 2005. Evaluation of stakeholder influence in the implementation of construction projects. International Journal of Project Management 23, 321-328. https://doi.org/10.1016/j.ijproman.2005.02.002

Petraš, J.C.E., 1997. Ranking the Sites for Low- and Intermediate-Level Radioactive Waste Disposal Facilities in Croatia. International Transactions in Operational Research 4, 237-249. https://doi.org/10.1111/j.1475-3995.1997.tb00080.x

R Core Team, 2019. R: A Language and Environment for Statistical Computing (Version 3.5.1). R Foundation for Statistical Computing, Vienna, Austria.

Roy, B., 1996. Multicriteria Methodology for Decision Aiding, Nonconvex Optimization and Its Applications. Springer Science \& Business Media.

Saaty, T.L., 1980. The analytic hierarchy process. McGraw Hill, New York.

Saaty, T.L., Gholamnezhad, H., 1982. High-Level Nuclear Waste Management: Analysis of Options. Environ Plann B Plann Des 9, 181-196. https://doi.org/10.1068/b090181

Saltelli, A., Ratto, M., Andres, T., Campolongo, F., Cariboni, J., Gatelli, D., Saisana, M., Tarantola, S., 2008. Global Sensitivity Analysis: The Primer. John Wiley \& Sons, Ltd.

Schwenk-Ferrero, A., Andrianov, A., 2017. Nuclear Waste Management Decision-Making Support with MCDA. Science and Technology of Nuclear Installations 2017, 20. https://doi.org/10.1155/2017/9029406

Shrader-Frechette, K., 2000. Duties to future generations, proxy consent, intra-and intergenerational equity: The case of nuclear waste. Risk Anal 20, 771-778.

Stiglitz, J.E., 2002. New perspectives on public finance: recent achievements and future challenges. Journal of Public Economics 86, 341-360.

US DOE, 1986. A Multiattribute Utility Analysis of Sites Nominated for Characterization for the First Radioactive-Waste Repository: A Decision-Aiding Methodology (No. DOE/RW-0074). Washington, DC.

US NWTRB, 2015. Designing a Process for Selecting a Site for a Deep-Mined, Geologic Repository for High-Level Radioactive Waste and Spent Nuclear Fuel - Detailed Analysis. United States Nuclear Waste Technical Review Board, Arlington, VA.

$\mathrm{Xu}$, D.-L., 2009. Assessment of nuclear waste repository options using the ER approach. Int. J. Info. Tech. Dec. Mak. 08, 581-607. https://doi.org/10.1142/S021962200900351X 
Refer to as: Diaz-Maurin, F.; Yu, J.; Ewing, R.C. Socio-technical multi-criteria evaluation of long-term spent nuclear fuel management strategies: A framework and method. Science of the Total Environment In press. Available at: 10.31223/X5459S.

\section{Tables}


Refer to as: Diaz-Maurin, F.; Yu, J.; Ewing, R.C. Socio-technical multi-criteria evaluation of long-term spent nuclear fuel management strategies: A framework and method. Science of the Total Environment In press. Available at: 10.31223/X5459S.

Table B.1. Evaluation of main multi-criteria methods according to desirable properties for social multi-criteria evaluation. Source: after Munda (2008, Table 5.5), except for STMCE (this paper).

\begin{tabular}{lllllllll}
\hline & Comp. & Imp. Coef. & Mix. Inf. & Simpl. & Hier. & Discr. Prob. & Tresh. & Confl. Anal. \\
\hline AHP & High & No & No & Low & Yes & No & No & No \\
ELECTRE & Low & Not clear & Partly & Low & No & Yes & Yes & No \\
NAIADE & Medium & No & Yes & Low & No & Yes & Yes & Yes \\
PROMETHEE & High & No & No & Medium & No & Yes & Yes & No \\
STMCE & Medium & Partly & Partly & Medium & Yes $^{3}$ & Yes & Yes $^{4}$ & Yes $^{3}$
\end{tabular}

Abbreviations used: Comp., compensation; Confl. Anal., conflict analysis; Discr. Prob., discrete decision problem; Hier., hierarchy; Imp. Coef., importance coefficient; Mix. Inf., mixed information; Simpl., simplicity; Thresh., thresholds. Notes: (1) in the conflict analysis only; (2) across the multi-criteria evaluation and social impact (conflict) analysis only; (3) hierarchy of dimensions in the multi-criteria evaluation; (4) indifference thresholds only. 
Refer to as: Diaz-Maurin, F.; Yu, J.; Ewing, R.C. Socio-technical multi-criteria evaluation of long-term spent nuclear fuel management strategies: A framework and method. Science of the Total Environment In press. Available at: 10.31223/X5459S.

Table B.2. Comparison of previous applications of multi-criteria analysis methods for nuclear waste management.

Abbreviations used: AHP, analytic hierarchy process; card., cardinal; deter., deterministic; CoRWM, UK's Committee on radioactive waste management; DUT, discounted utility theory; ER, evidential reasoning; fuz., fuzzy; HLW, high-level waste; ILW, intermediatelevel waste; LLW, low-level waste; MAUT, multi-attribute utility theory; MAVT, multi-attribute value theory; MCDA, multi-criteria decision analysis; MUA, multi-attribute utility analysis; ord., ordinal; SNF, spent nuclear fuel; STMCE, socio-technical multi-criteria evaluation; unspec., unspecified.

\begin{tabular}{|c|c|c|c|c|c|c|c|c|c|}
\hline Reference & Country & Level & Process & Waste type & $\begin{array}{l}\text { Social } \\
\text { actors }\end{array}$ & Method & $\begin{array}{l}\text { Linear } \\
\text { compensation } \\
\text { effect }\end{array}$ & $\begin{array}{l}\text { Type of } \\
\text { aggregation }\end{array}$ & $\begin{array}{l}\text { Type of } \\
\text { preferential } \\
\text { information }\end{array}$ \\
\hline $\begin{array}{l}\text { Saaty and } \\
\text { Gholamnezhad } \\
\text { (1982) }\end{array}$ & USA & National & Disposal & HLW/SNF & No & AHP & Partial & $\begin{array}{l}\text { Single } \\
\text { criterion }\end{array}$ & $\begin{array}{l}\text { Deter., card., } \\
\text { non-deter. }\end{array}$ \\
\hline $\begin{array}{l}\text { U.S. Department } \\
\text { of Energy (1986) }\end{array}$ & USA & National & Disposal & HLW/SNF & Ad hoc & MUA & Partial & $\begin{array}{l}\text { Single } \\
\text { criterion }\end{array}$ & Deter., ord. \\
\hline Briggs et al. (1990) & unspec. & National & $\begin{array}{l}\text { Storage, } \\
\text { disposal }\end{array}$ & $\begin{array}{l}\text { LLW/ILW, } \\
\text { HLW/SNF }\end{array}$ & No & PROMETHEE & Partial & Outranking & $\begin{array}{l}\text { Deter., card., } \\
\text { ord. }\end{array}$ \\
\hline $\begin{array}{l}\text { Delhaye et al. } \\
\text { (1991) }\end{array}$ & unspec. & National & unspec. & unspec. & No & ORESTE & Partial & Outranking & Deter., ord. \\
\hline $\begin{array}{l}\text { Keeney and von } \\
\text { Winterfeldt (1994) }\end{array}$ & USA & National & Disposal & HLW/SNF & No & MUA & Partial & $\begin{array}{l}\text { Single } \\
\text { criterion }\end{array}$ & Deter., ord. \\
\hline Petraš (1997) & Croatia & National & Disposal & LLW/ILW & No & PROMETHEE & Partial & Outranking & $\begin{array}{l}\text { Deter., card., } \\
\text { ord. }\end{array}$ \\
\hline $\begin{array}{l}\text { Atherton and } \\
\text { French (1998) }\end{array}$ & UK & National & $\begin{array}{l}\text { Storage, } \\
\text { disposal }\end{array}$ & unspec. & No & DUT & Partial & $\begin{array}{l}\text { Single } \\
\text { criterion }\end{array}$ & Deter., ord. \\
\hline $\begin{array}{l}\text { CoRWM in } \\
\text { Morton et al. } \\
(2009)\end{array}$ & UK & National & $\begin{array}{l}\text { Storage, } \\
\text { disposal }\end{array}$ & $\begin{array}{l}\text { LLW/ILW, } \\
\text { HLW/SNF }\end{array}$ & Ad hoc & unspec. & unspec. & unspec & unspec. \\
\hline Xu (2009) & Belgium & National & Disposal & LLW/ILW & Yes & ER & Total & $\begin{array}{l}\text { Single } \\
\text { criterion }\end{array}$ & $\begin{array}{l}\text { Deter., card., } \\
\text { non-deter., ord. }\end{array}$ \\
\hline $\begin{array}{l}\text { Kalinina and } \\
\text { Samsa (2016) }\end{array}$ & USA & National & $\begin{array}{l}\text { Storage, } \\
\text { disposal }\end{array}$ & HLW/SNF & Ad hoc & MUA & Partial & $\begin{array}{l}\text { Single } \\
\text { criterion }\end{array}$ & Deter., ord. \\
\hline $\begin{array}{l}\text { Schwenk-Ferrero } \\
\text { and Andrianov } \\
(2017)\end{array}$ & unspec. & $\begin{array}{l}\text { Local, } \\
\text { multi- } \\
\text { national, } \\
\text { regional }\end{array}$ & $\begin{array}{l}\text { Storage, } \\
\text { disposal }\end{array}$ & HLW/SNF & Ad hoc & MAVT & Partial & $\begin{array}{l}\text { Single } \\
\text { criterion }\end{array}$ & Deter., ord. \\
\hline $\begin{array}{l}\text { Diaz-Maurin et al. } \\
\text { (2021) - this paper }\end{array}$ & USA & $\begin{array}{l}\text { Local, state, } \\
\text { regional }\end{array}$ & $\begin{array}{l}\text { Storage, } \\
\text { disposal }\end{array}$ & SNF & Yes & STMCE & Partial & Outranking & $\begin{array}{l}\text { Deter., card., } \\
\text { non-deter., ord., } \\
\text { fuz. }\end{array}$ \\
\hline
\end{tabular}


Refer to as: Diaz-Maurin, F.; Yu, J.; Ewing, R.C. Socio-technical multi-criteria evaluation of long-term spent nuclear fuel management strategies: A framework and method. Science of the Total Environment In press. Available at: 10.31223/X5459S.

\section{Figures}

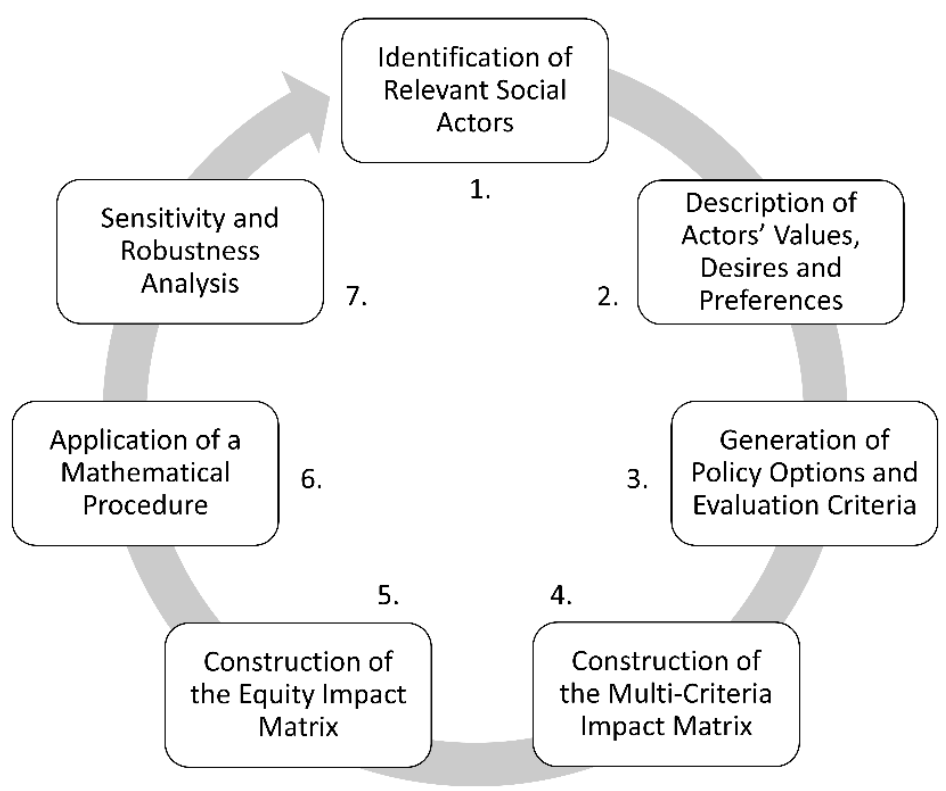

Fig. B.1. Main steps of the social multi-criteria evaluation process (adapted from Munda, 2009). 
Refer to as: Diaz-Maurin, F.; Yu, J.; Ewing, R.C. Socio-technical multi-criteria evaluation of long-term spent nuclear fuel management strategies: A framework and method. Science of the Total Environment In press. Available at: 10.31223/X5459S.



Fig. B.2. Membership functions of the linguistic variables (adapted from Munda, 2009). Note: Each membership function assumes a standard deviation $\sigma=\frac{1}{6}$ so that fuzziness exists only between linguistic variables that are directly adjacent. 